\title{
Early Implementation of Veno-Venous Hemofiltration and Use of Rotational Atherectomy in a Patient with ST-Elevation Myocardial Infarction Complicated by Cardiogenic Shock- case report.
}

Monika Durak ${ }^{1}$, Marek Tomala ${ }^{1}$, Bartłomiej Nawrotek ${ }^{1}$, Andrzej Machnik ${ }^{1}$, and Jacek Legutko $^{1}$

${ }^{1}$ Jagiellonian University Medical College

December 19, 2020

\begin{abstract}
We report a patient with cardiogenic shock (CS) in the course of acute right ventricular myocardial infarction (MI). Our case highlights the use of continuous veno-venous hemofiltration as a novel treatment option for acute kidney injury in the setting of CS and the use of rotational_atherectomy in patients with MI.

\section{Hosted file}

Main_Document_submission_07_12_2020.pdf available at https://authorea.com/users/383874/ articles/499702-early-implementation-of-veno-venous-hemofiltration-and-use-ofrotational-atherectomy-in-a-patient-with-st-elevation-myocardial-infarction-complicatedby-cardiogenic-shock-case-report
\end{abstract}




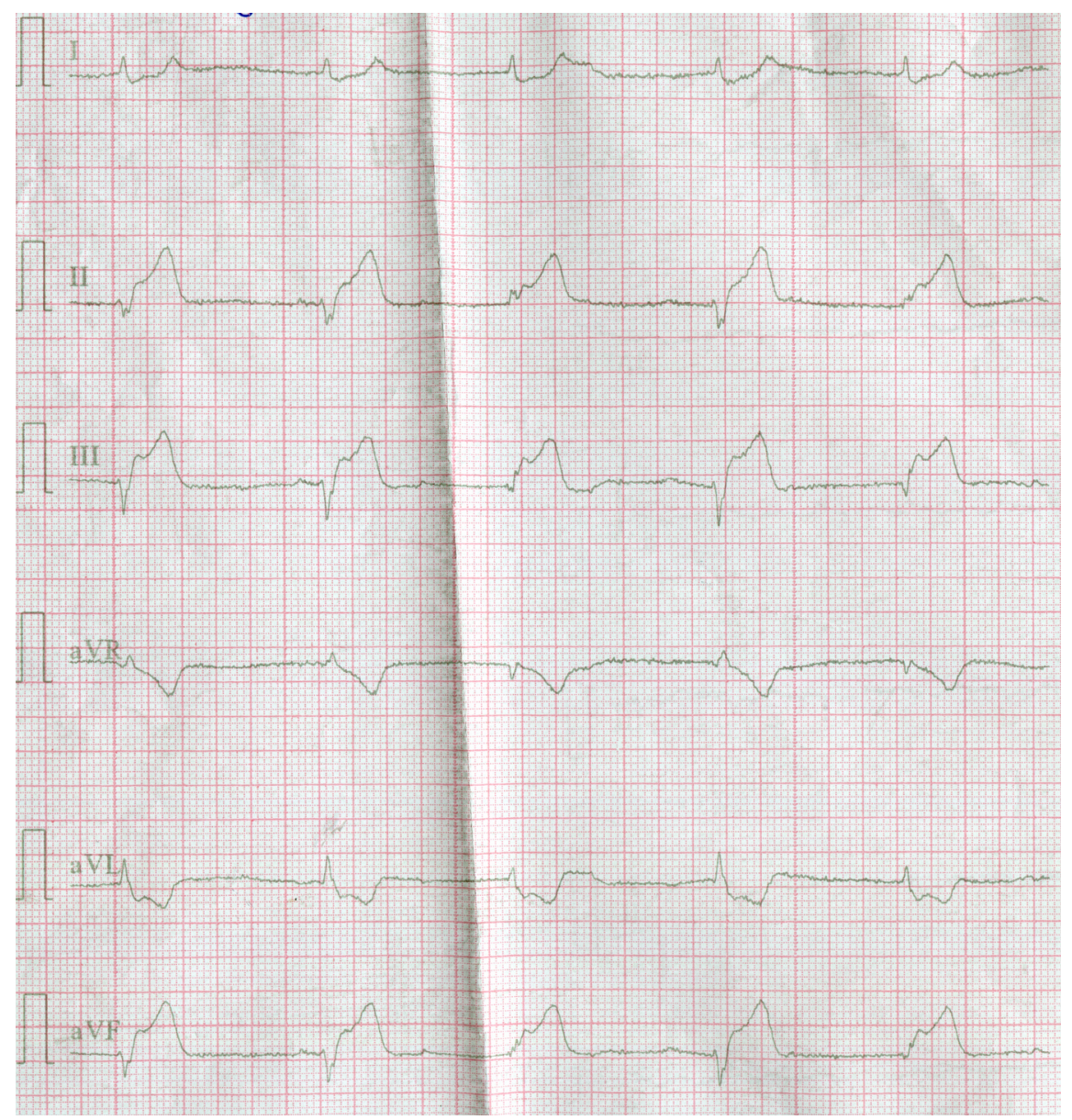








